\title{
Energia Eólica: Identificação e hierarquização dos riscos associados a projetos de investimento
}

\author{
Wind Energy: Identification and ranking of risks associated with investment projects \\ Energía Eólica: Identificación y ranking de riesgos asociados a proyectos de inversión
}

Recebido: 19/10/2021 | Revisado: 28/10/2021 | Aceito: 07/11/2021 | Publicado: 11/11/2021

\author{
Elizabeth Mayumi Ono \\ ORCID: https://orcid.org/0000-0002-2805-9413 \\ Universidade Estadual de Campinas, Brasil \\ E-mail: bethmayumi@gmail.com \\ João Maurício Rosário \\ ORCID: https://orcid.org/0000-0002-5347-4029 \\ Universidade Estadual de Campinas, Brasil \\ E-mail: rosario@fem.unicamp.br \\ Andrey Pimentel Aleluia Freitas \\ ORCID: https://orcid.org/0000-0003-0136-5696 \\ Universidade Federal Fluminense, Brasil \\ E-mail: andreyfreitas@id.uff.br \\ João Alberto Neves dos Santos \\ ORCID: https://orcid.org/0000-0002-4812-6214 \\ Universidade Federal Fluminense, Brasil \\ E-mail: joaoneves@id.uff.br
}

\begin{abstract}
Resumo
O conceito de desenvolvimento sustentável faz com que os investimentos, em tempos de crise econômica, sejam relacionados a aspectos ambientais, sobretudo os que contemplam fontes de energia renováveis. Nesse contexto, por sua característica física e climática amplamente favorável, o Brasil apresenta elevado potencial para a exploração de fontes de energias naturais alternativas. Nessa linha, tais questões justifiquem o crescimento recente de projetos dedicados à geração de energia eólica no Brasil. Não obstante, apesar dos benefícios amplos contemplados por projetos no setor, os elevados níveis de incerteza podem representar obstáculos aos investidores. Assim, por meio de uma abordagem prévia dos riscos associados a projetos de investimento em fontes renováveis de energia eólica, podese identificar uma estrutura crítica que venha a contribuir com a visão crítica dos investidores, proporcionando maiores níveis de segurança às suas intenções. Dessa forma, buscou-se identificar os principais fatores de riscos associados à fonte geradora de energia eólica, destacados na literatura. Em seguida, a partir da elaboração de uma Survey, um questionário foi aplicado em uma amostragem não probabilística, caracterizada por profissionais e especialistas atuantes no setor. Os dados obtidos foram avaliados através da análise multivariada, cujo objetivo foi desenvolver um referencial crítico para auxiliar projetos de investimento, planejamento e gestão, onde os resultados identificaram 34 fatores de risco associados a fontes de energia eólica no Brasil, que foram hierarquizados, conforme os graus de impacto. Em ordem decrescente, destacam-se: burocracia; risco país; licenças ambientais; riscos contratuais e riscos regulatórios.
\end{abstract}

Palavras-chave: Energias renováveis; Energia eólica; Projetos de energia; Gerenciamento de riscos.

\begin{abstract}
The concept of sustainable development makes investments, in times of economic crisis, related to environmental aspects, especially those that include renewable energy sources. In this context, due to its highly favorable physical and climatic characteristics, Brazil has a high potential for exploring alternative natural energy sources. Along these lines, such issues justify the recent growth of projects dedicated to wind power generation in Brazil. Nevertheless, despite the broad benefits contemplated by projects in the sector, high levels of uncertainty can pose obstacles to investors. Thus, through a prior approach to the risks associated with investment projects in renewable sources of wind energy, it is possible to identify a critical structure that will contribute to the critical view of investors, providing greater levels of security for their intentions. Thus, we sought to identify the main risk factors associated with the generating source of wind energy, highlighted in the literature. Then, from the elaboration of a Survey, a questionnaire was applied in a non-probabilistic sample, characterized by professionals and specialists working in the sector. The data obtained were evaluated through multivariate analysis, whose objective was to develop a critical framework to assist investment, planning and management projects, where the results identified 34 risk factors associated with wind energy sources in Brazil, which were ranked according to the degrees of impact. In descending
\end{abstract}


order, the following stand out: bureaucracy; country risk; environmental licenses; contractual risks and regulatory risks.

Keywords: Renewable energies; Wind energy; Energy projects; Risk management.

\begin{abstract}
Resumen
El concepto de desarrollo sostenible realiza inversiones, en tiempos de crisis económica, relacionadas con aspectos ambientales, especialmente aquellos que incluyen fuentes de energía renovables. En este contexto, por sus características físicas y climáticas altamente favorables, Brasil tiene un alto potencial para explorar fuentes alternativas de energía natural. En esta línea, tales cuestiones justifican el reciente crecimiento de proyectos dedicados a la generación de energía eólica en Brasil. No obstante, a pesar de los amplios beneficios que contemplan los proyectos en el sector, los altos niveles de incertidumbre pueden representar obstáculos para los inversores. Así, mediante un abordaje previo de los riesgos asociados a los proyectos de inversión en fuentes renovables de energía eólica, es posible identificar una estructura crítica que contribuirá a la visión crítica de los inversores, aportando mayores niveles de seguridad a sus intenciones. Así, buscamos identificar los principales factores de riesgo asociados a la fuente generadora de energía eólica, resaltados en la literatura. Luego, a partir de la elaboración de una Encuesta, se aplicó un cuestionario en una muestra no probabilística, caracterizada por profesionales y especialistas que laboran en el sector. Los datos obtenidos fueron evaluados a través de análisis multivariante, cuyo objetivo fue desarrollar un marco crítico para ayudar a los proyectos de inversión, planificación y gestión, donde los resultados identificaron 34 factores de riesgo asociados a las fuentes de energía eólica en Brasil, los cuales fueron clasificados según los grados de impacto. En orden descendente destacan: burocracia; riesgo país; licencias ambientales; riesgos contractuales y riesgos regulatorios.
\end{abstract}

Palabras clave: Energías renovables; Energía eólica; Proyectos energéticos; Gestión de riesgos.

\title{
1. Introdução
}

No cenário atual, no qual crescentes impactos e danos ao meio ambiente, proporcionados, principalmente, pela emissão de gases gerados através da queima de combustíveis fósseis, o desenvolvimento e a utilização de fontes de energias renováveis é visto, por especialistas, como uma forma de minimizar os problemas causados pela emissão dos Gases de Efeito Estufa (GEE). Sendo assim, considerando a necessidade de obtenção de recursos naturais que tenham características de regeneração e não apresentem significativos impactos indesejados ao meio ambiente, a busca por fontes geradoras de energias alternativas é ainda mais urgente.

Ademais, à medida que surgem necessidades de investimento em fontes de energia renováveis, aumenta também o número de projetos destinados à captação de recursos financeiros para essa finalidade e para que os projetos de investimentos se mostrem tangíveis, eles precisam contemplar todos os riscos e incertezas presentes.

No que diz respeito aos projetos de energia sustentável, os riscos abordados por pesquisadores apresentam características multidimensionais e surgem a partir de condições relacionadas a alguns fatores, dentre eles: tecnológicos; ambientais, políticos, sociais econômicos e legais, sempre levando em conta as especificidades de cada país ou região e as características e interesses das partes interessadas (Perea et al., 2018).

Outro fator que corrobora a escolha por energias renováveis, é o que fato de que as energias renováveis apresentem um perfil de potencial de risco inferior às fontes de energia convencionais, pois essas são vinculadas aos preços dos combustíveis fósseis, que envolvem considerável exposição a fatores de risco financeiros, regulatórios, tecnológicos, geopolíticos, ambientais, dentre outros. Não obstante, esses riscos geralmente são mitigados por políticas públicas protecionistas, que geram impactos aos consumidores, como, por exemplo, a aplicação dos impostos nas contas de energia (Bhattacharya \& Kojima, 2012).

Vale ressaltar que, como afirmam Simas e Pacca (2013), uma das fontes que vem recebendo cada vez mais atenção nos últimos anos é a eólica, impulsionada, tanto por preços competitivos, como pelo fortalecimento do mercado fornecedor, e pelo uso de novas tecnologias (Venchiarutti, 2012). Outro ponto que pesa a favor desse tipo de geração de energia elétrica é seu baixo impacto ambiental (Pereira Neto, 2014). Em suma, esses são os principais motivos que incitaram o presente estudo 
Research, Society and Development, v. 10, n. 14, e490101422011, 2021

(CC BY 4.0) | ISSN 2525-3409 | DOI: http://dx.doi.org/10.33448/rsd-v10i14.22011

\begin{tabular}{|l|l|}
\hline & Riscos arqueológicos \\
\cline { 2 - 3 } & Atraso na emissão das licenças ambientais \\
\cline { 2 - 3 } & Poluição sonora e visual \\
\cline { 2 - 3 } & Ameaça à animais e aves da região \\
\cline { 2 - 3 } & Mudança climática e regime dos ventos mais baixos \\
\hline
\end{tabular}

Fonte: Autores.

Após a identificação e estruturação classificatória dos principais fatores de risco atinentes ao processo de implantação de projetos e gestão de geração de energia eólica, tal como destacadas no Quadro 1, a etapa seguinte desta investigação foi caracterizada pela estruturação de uma pesquisa de natureza quantitativa, com foco na experiência de especialistas do setor, a fim de identificar os graus de impacto de cada fator de risco, tanto na implantação, como na gestão de projetos de geração de energia eólica, com destaque para as especificidades locais e interesses de investidores e gestores no Brasil.

A pesquisa feita por meio do questionário permitiu que os fatores identificados na bibliografia, e depois classificados, pudessem, finalmente, ser hierarquizados, para a produção de um guia de referência no intuito de auxiliar futuros projetos de implantação e gestão desse tipo de energia renovável em âmbito nacional.

O objetivo deste material é identificar, através de uma revisão da literatura, os principais fatores de risco relacionados a implementação do sistema gerador de energia eólica no Brasil. Com base nessas informações, busca-se classificá-los, por meio de pesquisa quantitativa, tendo como base a percepção de especialistas atuantes no setor.

Por fim, objetiva-se hierarquizar cada evento de risco, de forma ampla e dentro da sua categoria de risco, considerando os respectivos níveis de impacto para a implementação de novos projetos, conforme a visão dos especialistas entrevistados. Dessa forma, torna-se possível a elaboração de um referencial técnico que contemple os principais fatores de risco e possa auxiliar projetos de investimento para a geração de energia eólica no mercado brasileiro.

\section{Revisão da Literatura}

O material utilizado nesta pesquisa foi obtido a partir do um levantamento bibliográfico a respeito dos principais fatores de riscos associados a projetos de investimentos, implantação e gestão de geração de energia eólica na literatura, onde destacam-se os seguintes autores: Ioannou, Angus e Brennan (2017); Santini (2017); Tavares (2016); Sovernigo (2009); Bittencourt (2018); Trannin (2016); Meireles (2018); Gomes (2017); Kucukali (2015).

A partir do levantamento bibliográfico, foi desenvolvido e estruturado um questionário que contemplou seis grandes categorias de risco: político, econômico, tecnológico, social, legal e ambiental, que por sua vez, contemplam 34 fatores de risco (Quadro 1). Essa organização objetiva identificar e hierarquizar os principais fatores de risco com impacto em projetos de investimento em energia eólica, de modo a elaborar um referencial técnico para auxiliar em futuros projetos no setor, em âmbito nacional.

$\mathrm{O}$ instrumento de pesquisa foi elaborado a partir do grupo de fatores de riscos listados acima, que foram associados a projetos de investimento e gestão de geração de energia eólica, caracterizados pela sua frequência, conforme os níveis de efeito ou impacto causados em virtude da ocorrência de cada fator. Assim, os respondentes foram solicitados a assinalar, de acordo com seus conhecimentos e visão de mercado, os níveis de relevância de cada fator de risco, considerando uma escala básica de valores entre 0 e 10 , onde 0 (zero) significa impacto nulo e 10 impacto máximo.

Para a aplicação da abordagem estatística nos dados coletados, foi utilizado o software R, que por sua vez, foi associado a elaboração de representações gráficas que melhor se adequassem aos dados, a fim de tornar possível a elaboração de diagramas estatísticos com as respectivas variabilidades nos graus de ocorrência e impacto, podendo assim, hierarquizá-los. 
De um modo geral, o objetivo desta abordagem foi analisar as respostas e consolidar os resultados de maneira quantitativa, para que futuros investidores possam considerar, com elevado grau de previsibilidade, os potenciais níveis de impacto, nos processos de implementação e gestão de projeto destinados à exploração e geração de energia eólica no país.

\subsection{Aspectos gerais associados à energia eólica}

A radiação solar é o principal responsável pela geração da energia eólica, pois os ventos são gerados a partir do aquecimento da superfície terrestres, e dados apontam que aproximadamente $2 \%$ da energia solar absorvida pela terra é convertida em energia cinética dos ventos. Mesmo que pequeno esse percentual representa centena de vezes a potência anual instalada nas centrais elétricas do mundo (Brito, 2008).

Segundo Reis (2009), o aproveitamento do vento para geração de energia elétrica é feito através grandes aerogeradores implantados em terra ou no mar. Estes aerogeradores são providos de uma torre metálica com altura entre 25 e $80 \mathrm{~m}$ e turbinas com duas ou três pás com capacidade de produção de até $5 \mathrm{MW}$.

A velocidade mínima do vento necessária varia entre $10-15 \mathrm{~km} / \mathrm{h}$ e a velocidade ideal é entre $50-60 \mathrm{~km} / \mathrm{h}$. Caso haja tempestade, as pás e o rotor são travados quando a velocidade do vento for superior a $90 \mathrm{~km}$, podendo o aerogerador suportar velocidades até $200 \mathrm{~km} / \mathrm{h}$ sem causar danos. Há ainda proteção contra raios e microprocessadores utilizados para ajustagem de ângulos das pás às condições do vento e a manutenção de um output de corrente elétrica uniforme ligado à rede de distribuição elétrica.

De acordo com a ABEEOLICA (2020), a energia eólica é atualmente a segunda fonte da matriz elétrica nacional, cuja participação corresponde a com cerca de $10,1 \%$ de participação graças à qualidade de nossos ventos. Temos 600 parques eólicos em funcionamento, com mais de 7.532 aerogeradores em 12 estados.

Em termos mundiais, no ano de 2018, o Brasil foi classificado como o sétimo país no Ranking Mundial de capacidade eólica instalada, elaborado pelo Global Wind Energy Council (GWEC). O desenvolvimento da energia eólica no Brasil já acumula um investimento de mais de US\$ 32 bilhões nos últimos sete anos. Em 2018, por exemplo, o investimento foi de US\$ 1,3 bilhão. O Quadro 2 apresenta dados da matriz elétrica brasileira, onde mostra que a energia eólica ocupa a $2^{a}$ posição, ficando atrás somente da energia hidrelétrica.

Quadro 2: Caracterização atual da matriz energética nacional.

\begin{tabular}{|l|c|c|}
\hline \multicolumn{1}{|c|}{ Fonte de energia } & Quantidade (GW) & Participação \\
\hline Hidrelétrica & 103,03 & $\mathbf{5 8 , 8 \%}$ \\
\hline Eólica & $\mathbf{1 7 , 7 5}$ & $8, \mathbf{1 \%}$ \\
\hline Biomassa & 15,23 & $8,5 \%$ \\
\hline Gás Natural & 14,95 & $5,1 \%$ \\
\hline Petróleo & 9,01 & $3,6 \%$ \\
\hline PCH e GCH & 6,26 & $2,0 \%$ \\
\hline Carvão & 3,58 & $1,9 \%$ \\
\hline Fotovoltaica & 3,29 & $1,1 \%$ \\
\hline Nuclear & 1,99 & \\
\hline
\end{tabular}

Fonte: ANEEL/ABEEOLICA (2019).

A Figura 1 apresentada um gráfico que mostra a quantidade de residências brasileiras que já poderiam ser abastecidas apenas com a geração de energia eólica em 2019. 
Figura 1: Quantidade de residências abastecidas por energia eólica em 2019.

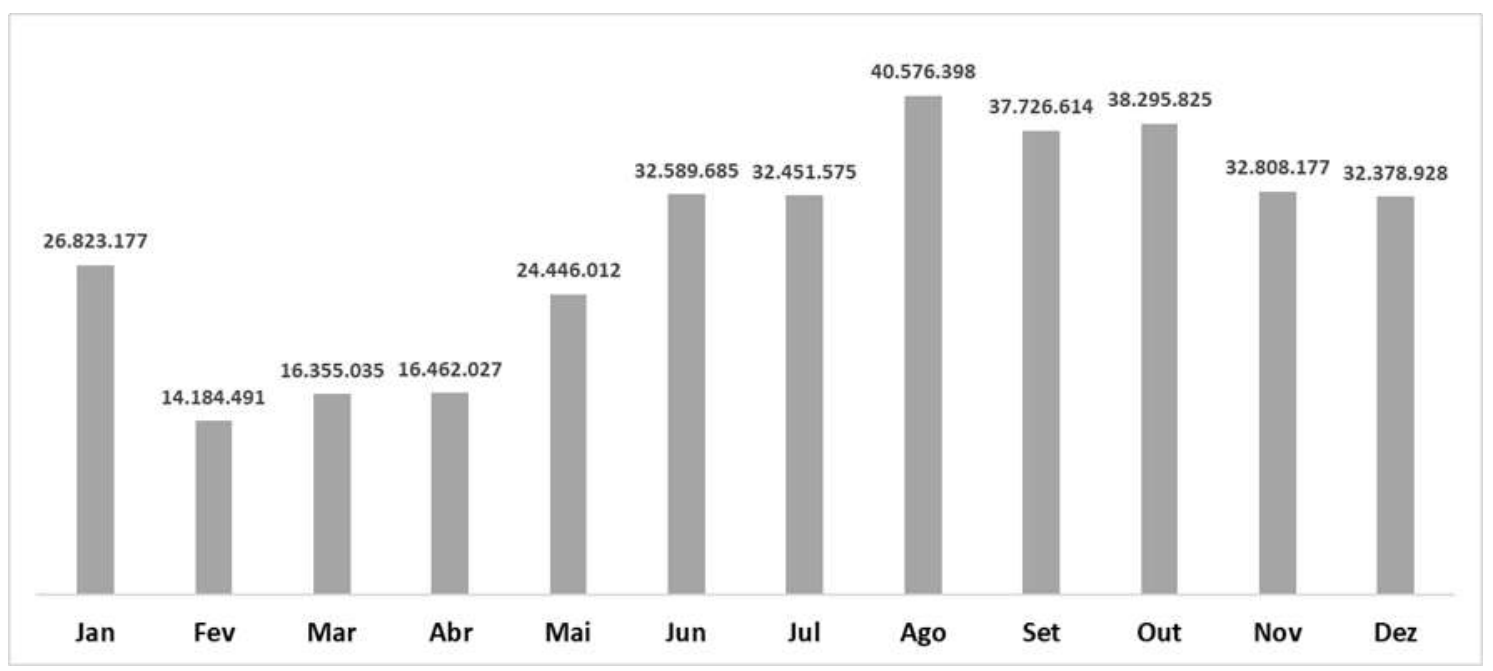

Fonte: ABEEOLICA (2019).

Como consequência, a Figura 2 indica a quantidade emitida, em toneladas, de CO2 que poderia ter sido evitada em 2019.

Figura 2: Toneladas de emissão de CO2 evitadas em 2019.

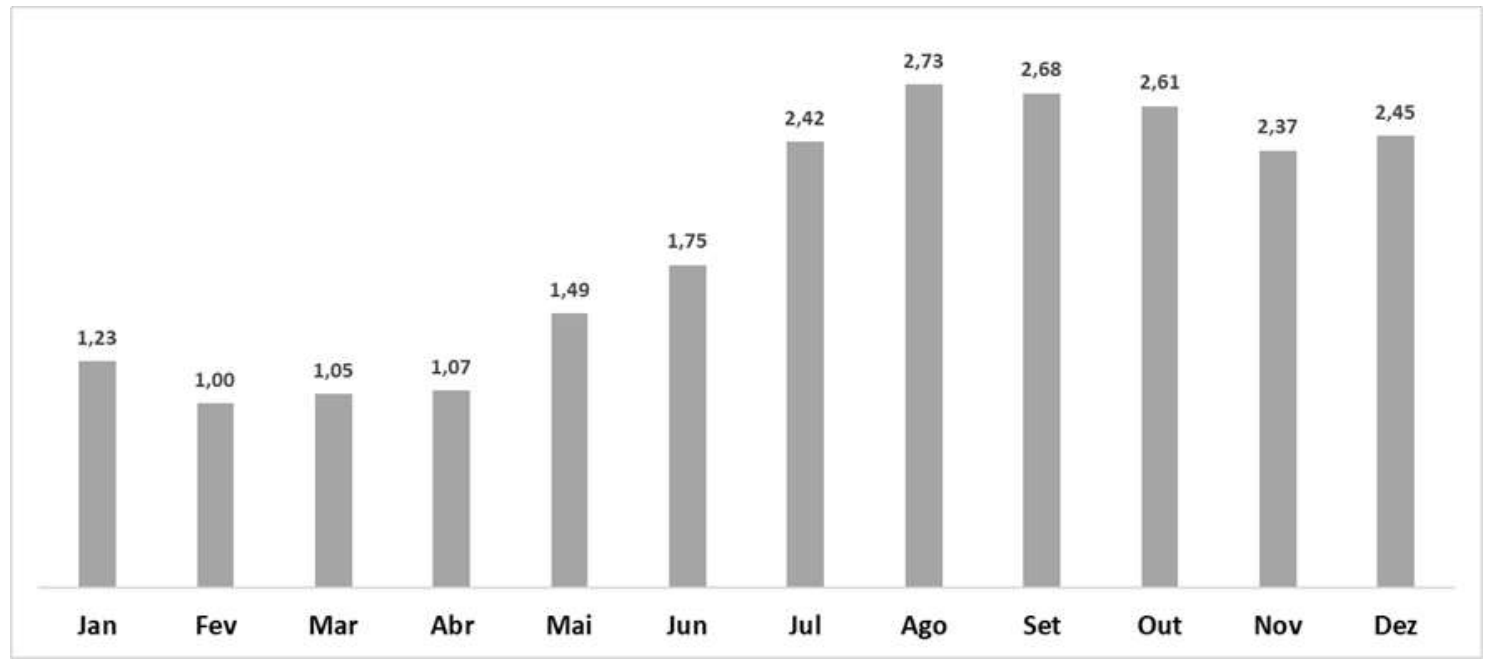

Fonte: ABEEOLICA (2019).

Por meio da Figura 1, pode-se verificar que, em média, 30 milhões de residências poderiam ser abastecidas mensalmente somente por fontes de energia eólica, valor que representa quase metade do total de residências do Brasil (IBGE, 2021). Como consequência, conforme dados da Figura 3, temos que 22,85 milhões de toneladas de CO2 poderiam ter sido evitadas em 2019.

O panorama da capacidade eólica no Brasil, destacado pelo Quadro 3, mostra a fonte de energia eólica apresenta caráter muito promissor, podendo alcançar uma capacidade de 272,2 TWh/ano, com destaque para a região Nordeste do país. 
Quadro 3: Capacidade atual e potencial eólico nas regiões do território nacional.

\begin{tabular}{|l|c|c|}
\hline \multicolumn{1}{|c|}{ Região } & Capacidade Atual (GW) & Potencial de Capacidade (THh/ano) \\
\hline Norte & 12,8 & 26,4 \\
\hline Nordeste & 75,0 & 144,3 \\
\hline Sul & 22,8 & 41,1 \\
\hline Sudeste & 29,7 & 54,9 \\
\hline Centro-Oeste & 3,1 & 5,4 \\
\hline Total Brasil & $\mathbf{1 4 3 , 5}$ & $\mathbf{2 7 2 , 2}$ \\
\hline
\end{tabular}

Fonte: ABEEOLICA (2019).

\subsection{Aspectos positivos da energia eólica}

Diante da abordagem relacionada a fontes de energias renováveis, uma questão pode ser levantada: Por que apostar no aproveitamento da energia eólica em detrimento de outras fontes de energias renováveis?

Esse questionamento pode ser respondido pelo fato de, apesar de que nenhuma das fontes de energias renováveis possa satisfazer a $100 \%$ as necessidades de consumo, a energia eólica é aproveitada até ao máximo do seu potencial, pois é uma energia limpa, não causa poluição atmosférica (não produz dióxido de carbono, dióxido de enxofre, responsáveis pelo "efeito de estufa" e pela "chuva ácida") e não produz ou utiliza qualquer material radioativo.

Os custos estão em decréscimo, motivados pela evolução de novas tecnologias. Em médias, 6 meses é o prazo para se ter a recuperação do que foi investido na implantação de um projeto. Além disso, os impactos ambientais e interferências eletromagnéticas podem ser minimizados durante o planejamento da localização. As atividades agrícolas podem ser desenvolvidas ao redor das torres.

Por fim, a vida útil de um gerador costuma ser de 20 anos. Após este período toda a estrutura pode ser desmontada, devolvendo ao local sua característica original.

\subsection{Risco em projetos}

De acordo com a Norma NBR ISO 31000:2018, risco é o efeito da incerteza nos objetivos traçados. Em complemento a essa visão, temos que:

i. Um efeito resulta de um desvio em relação ao objetivo traçado, podendo ser positivo e/ou negativo;

ii. Os objetivos podem contemplar diferentes aspectos, tais como: metas financeiras, de saúde e segurança e ambientais. E podem ser aplicados em diferentes níveis organizacionais, tais como: estratégico, em toda a organização, de projeto, de produto e de processo;

iii. O risco é, muitas vezes, caracterizado pela referência aos eventos potenciais e suas consequências, ou uma combinação destes;

iv. O risco é muitas vezes expresso em termos de uma combinação de consequências de um evento (incluindo mudanças nas circunstâncias) e a probabilidade de ocorrência associada;

v. A incerteza é o estado, mesmo que parcial, da deficiência das informações relacionadas a um evento, abrangendo seu conhecimento e compreensão, a partir das consequências ou probabilidade de surgimento.

Sob uma visão mais aplicada, De Cicco e Fantazzini (2003) entendem que a possibilidade de ocorrência segue por duas vertentes: especulativas, com característica dinâmica; e pura, com características estáticas. Nessa visão, a principal diferença entre essas vertentes consiste na possibilidade de obtenção de ganhos ou perdas, quando os riscos forem especulativos; e somente possibilidade de perdas, quando não há nenhuma possibilidade de ganho ou de lucro, no caso dos riscos puros. 
Por fim, sob uma definição relacionada a riscos em projetos, Modarres (2006), Valeriano (1998) e Keeling (2006), consideram que, além da ocorrência de um efeito indesejado, seu significado pode ainda mostrar o quanto é provável de surgir e, caso ocorra, torna-se necessário compreender seu impacto gerado. Assim, temos que um risco pode ser configurado por um evento ou condição incerta que tem possibilidades especulativas (positivo ou negativo) de ocorrer sobre uma das variáveis de um projeto, como cronograma, custos, dimensão ou qualidade (PMI, 2017); e ainda, como um determinado conjunto de circunstâncias que, ao ocorrerem, terão efeito sobre a concretização dos objetivos do projeto (APM, 1997).

\section{Metodologia}

Por meio do aplicativo de gerenciamento de pesquisas Google Forms, o instrumento de pesquisa foi estruturado e enviado a 200 profissionais e pesquisadores no setor de energia, encontrados nas bases de dados da ABEEÓLICA (Associação Brasileira de Energia Eólica) e LinkedIn (Maior rede social profissional do mundo).

As respostas coletadas foram analisadas por meio da estatística inferencial, onde, por meio da análise multivariada, foi possível observar o comportamento dos fatores de riscos contemplados. Neste estudo foram ainda desenvolvidos, por meio da estatística descritiva, indicadores e correlações entre o perfil dos respondentes e os fatores de riscos presentes entre si. Com base do cálculo para dimensionamento da amostragem, considerou-se a Equação 1, onde, de acordo com Pinheiro (2011) devese aplicar em situações relacionadas a universos finitos.

$$
\boldsymbol{n}=\frac{\left(s^{2} \times z^{2} \times N\right)}{\left(s^{2} \times Z^{2}+e^{2}(N-1)\right)}=\frac{\left(0,25^{2} \times 1,96^{2} \times 200\right)}{\left(0,25^{2} \times 1,96^{2}+0,05^{2}(200-1)\right)}=65
$$

Eq1.

Onde:

- $\quad N$ é o universo de pessoas contempladas pela pesquisa.

- $\quad S$ é a variância amostral.

- $\quad e$ é o erro amostral.

- Z é o desvio padrão amostral

As variáveis de estudo para a amostra, contemplaram o universo total de pessoas e a variância amostral, tendo-se fixado o valor de 0,25, por se tratar de universos finitos (Pinheiro, 2011). A pesquisa é caracterizada por percentual de $95 \%$ de grau de confiabilidade nos dados apresentados e analisados, visto que no total de 200 entrevistados com uma margem de erro amostral de 5\%, desvio-padrão de 1,96 para esse nível de confiança (95\%). A Tabela 1 apresenta detalhamento das variáveis consideradas para o cálculo da amostragem.

Tabela 1: Variáveis de cálculo de amostragem.

\begin{tabular}{ccl}
\hline Variável & Valores assumidos da pesquisa & \multicolumn{1}{c}{ Descrição } \\
\hline $\mathbf{N}$ & 200 & Universo Total de pessoas da pesquisa \\
\hline $\mathbf{S}$ & 0,25 & Variância amostral \\
\hline $\boldsymbol{e}$ & 0,05 & Erro amostral \\
\hline $\mathbf{Z}$ & 1,96 & Desvio-padrão amostral \\
\hline
\end{tabular}

Fonte: Autores.

O resultado do cálculo para o tamanho da amostra é igual a 65. Esse valor direciona a quantidade mínima de respondentes a serem abordados pela pesquisa. Como o valor total de respondentes foi igual a 84 indivíduos, a amostra foi considerada estatisticamente adequada e satisfatória aos critérios de validação de dimensionamento.

$\mathrm{Na}$ primeira etapa da pesquisa, os entrevistados responderam questões relacionadas aos 34 fatores de risco, presente 
nos 6 constructos (categorias de risco), onde se obteve 2.856 respostas. Desse valor, apenas uma resposta foi deixada em branco. Como medida de ajuste, a célula em branco foi tratada pelo critério de imputação pela média da variável correspondente, por ser um dos métodos mais adequados e amplamente empregado, conforme sugerem Hair et al. (2009).

Para a análise descritiva, três variáveis de caracterização (profissão, ramo de atividade e local) foram consideradas, tendo suas frequências absolutas e relativas dimensionadas. Para a descrição e o comparativo dos itens (fatores de risco) presentes nos constructos (categorias de risco), além das medidas tendência central e dispersão, foi ainda utilizado o intervalo percentílico bootstrap, considerando 95\% de confiança (Efron \& Tibshirani, 1993). Por fim, para a descrição dos indicadores criados foram usadas medidas de tendência central e dispersão.

Objetivando desenvolver indicadores para representar os constructos, a abordagem estatística foi direcionada para a aplicação da Análise Fatorial Exploratória (AFE), onde a dimensionalidade dos constructos foi verificada por meio do critério das Retas Paralelas (Hoyle \& Duvall, 2004) que torna possível considerara quantidade de dimensões do constructo.

A qualidade dos indicadores criados a partir da AFE foi verificada pela aplicação da análise de validade convergente e confiabilidade de cada constructo. A avaliação da validade convergente considera o critério da Variância Média Extraída AVE (Fornell \& Larcker, 1981), cujo valor representa percentual médio de variância compartilhada entre o constructo latente e seus respectivos itens. Este critério garante a validade convergente para valores da AVE acima de 50\% (Henseler, Ringle \& Sinkovics, 2009) ou 40\%, no caso de pesquisas exploratórias (Nunnally \& Bernstein, 1994).

Para verificar a confiabilidade foram utilizados os indicadores Alfa de Cronbach e Confiabilidade Composta (Chin, 1998). De acordo com Tenenhaus et al. (2005), esses indicadores devem apresentar valores acima de 0,70 para uma indicação de confiabilidade do constructo, ou valores acima de 0,60 no caso de pesquisas exploratórias (Hair et al., 2009).

Para avaliar se a utilização da AFE era adequada aos dados da pesquisa, foi utilizada a medida de adequação da amostra de Kaiser-Meyer-Olkin - KMO, que verifica a proporção da variância dos dados que pode ser considerada comum a todas as variáveis. Os valores desta medida variam entre 0 e 1 e a utilização da Análise Fatorial é adequada aos dados quando o KMO for maior ou igual 0,50, sendo que quanto mais próximo de 1 mais apropriada é a amostra à aplicação da AFE. Sendo assim, os constructos foram computados utilizando o método de extração das componentes principais (Freitas et al, 2021; Mingoti, 2007).

A Tabela 2 mostra os constructos e seus respectivos itens, associados a cada risco identificado na pesquisa. Importante destacar que o software utilizado nas análises foi o R (versão 4.0.2).

Tabela 2: Caracterização e identificação dos itens.

\begin{tabular}{cll}
\hline \multicolumn{1}{c}{ Constructo } & \multicolumn{1}{c}{ Item } \\
\hline \multirow{3}{*}{ Risco Político } & RP1 & $\begin{array}{l}\text { 1.1 Risco Regulatório (Mudanças nos esquemas de suporte a políticas, Responsabilidade perante } \\
\text { terceiros). }\end{array}$ \\
\cline { 2 - 3 } & RP2 & 1.2 Risco País (Instabilidade política, Eleições). \\
\cline { 2 - 3 } & RP3 & 1.3 Risco contratual (Previsão de penalidades por atraso e custos com licenças ambientais). \\
\cline { 2 - 3 } & RE1 & 2.1 Burocracia (Processos de aprovação complexos, Atrasos de licenças). \\
\cline { 2 - 3 } Risco Econômico & RE2 & 2.2 Mercado (Variabilidade de receita devido ao preço da eletricidade, Flutuação de demanda). \\
\cline { 2 - 3 } & RE3 & 2.3 Danos à reputação. \\
\cline { 2 - 3 } & RE4 & $\begin{array}{l}\text { 2.4 Financeiro/Fiscal (Custos de geração de energia eólica geralmente mais elevados do que os } \\
\text { baseados em recursos energéticos tradicionais, Riscos de financiamentos, Oscilação de taxa de } \\
\text { juros, Regime de tributação, Inflação). }\end{array}$ \\
\cline { 2 - 3 } Risco Social & RE5 & $\begin{array}{l}\text { 2.5 Abrangência dos Seguros (Por força maior, Pandemias, Necessidade do empreendedor a arcar } \\
\text { com indenizações que deveriam ser suportadas pela seguradora). }\end{array}$ \\
\cline { 2 - 3 } & RS1 & 3.1 Falta de Aceitação Pública, Mudança de consciência socioambiental da sociedade. \\
\cline { 2 - 3 } & RS2 & 3.2 Riscos para a saúde (Acidentes, Doenças agudas). \\
\cline { 2 - 3 } & RS3 & 3.3 Movimentos Sindicais.
\end{tabular}




\begin{tabular}{|c|c|c|}
\hline & RS4 & $\begin{array}{l}\text { 3.4 Pleitos de terceiros por indenizações não previstas (Prejuízo às atividades econômicas locais - } \\
\text { agricultura, pecuária, pesca, turismo). }\end{array}$ \\
\hline & RS5 & $\begin{array}{l}\text { 3.5 Riscos de Segurança (Custos para cumprimentos de requisitos de segurança, Burocracia } \\
\text { excessiva para avaliação de documentação de segurança). }\end{array}$ \\
\hline & RS6 & 3.6 Incremento dos conflitos com as comunidades tradicionais e indígenas. \\
\hline \multirow{10}{*}{ Risco Tecnológico } & RT1 & $\begin{array}{l}\text { 4.1 Operação e Manutenção (Falhas de Componentes, Fechamento de fábrica não programada } \\
\text { devido à falta de recursos, Geração de menos eletricidade ao longo do tempo do que o esperado). }\end{array}$ \\
\hline & RT2 & $\begin{array}{l}\text { 4.2 Desenvolvimento de Projetos (Perda de receita devido ao atraso do projeto, Escopo mal } \\
\text { detalhado, falha obter licenças necessárias, Falha no estudo eólico, Falta de comunicação). }\end{array}$ \\
\hline & RT3 & $\begin{array}{l}4.3 \text { Construção (Danos durante o transporte ou construção, Danos devidos a perigos naturais, } \\
\text { Falta de confiabilidade dos componentes). }\end{array}$ \\
\hline & RT4 & 4.4 Indisponibilidade de mão-de-obra qualificada. \\
\hline & RT5 & 4.5 Sabotagem, terrorismo, roubo \\
\hline & RT6 & $\begin{array}{l}\text { 4.6 Equipamentos e Mercado Fornecedor (Obsolescência dos equipamentos, Insolvência dos } \\
\text { fornecedores, Falta de insumos). }\end{array}$ \\
\hline & RT7 & 4.7 Infraestrutura. \\
\hline & RT8 & 4.8 Custo de Desmantelamento. \\
\hline & RT9 & 4.9 Riscos Logísticos, acessos a estradas. \\
\hline & RT10 & 4.10 Conexão da rede. \\
\hline \multirow{2}{*}{ Risco Legal } & RL1 & 5.1 Políticas energéticas e mudanças climáticas. \\
\hline & RL2 & 5.2 Ausência de legislação específica. \\
\hline \multirow{8}{*}{ Risco Ambiental } & RA1 & 6.1 Risco de dano ambiental com pagamento de multa. \\
\hline & RA2 & 6.2 Pegada de carbono e avaliação do ciclo de vida. \\
\hline & RA3 & 6.3 Topografia, geologia, hidrologia do empreendimento. \\
\hline & RA4 & 6.4 Riscos Arqueológicos. \\
\hline & RA5 & 6.5 Atrasos na emissão das licenças ambientais. \\
\hline & RA6 & 6.6 Poluição sonora e visual. \\
\hline & RA7 & 6.7 Ameaça à animais e aves da região. \\
\hline & RA8 & 6.8 Mudança climática e regime de ventos mais baixos. \\
\hline
\end{tabular}

Fonte: Autores.

\section{Análise dos Resultados}

\subsection{Análise estatística descritiva}

Um estudo quantitativo inicial foi aplicado e teve como principal objetivo, resumir, sumarizar e explorar o comportamento dos dados através de tabelas, gráficos e medidas de resumo numérico. Primeiramente, foram identificadas as variáveis de categorização conforme mostra a Tabela 3.

Tabela 3: Análise descritiva das variáveis de categorização.

\begin{tabular}{|c|c|c|c|}
\hline & & $\mathbf{N}$ & $\%$ \\
\hline \multirow{2}{*}{ Profissão } & Engenheiro & 51 & $60,71 \%$ \\
\hline & Outros & 33 & $39,29 \%$ \\
\hline \multirow{2}{*}{ Ramo de atividade da empresa } & Energia & 27 & $32,14 \%$ \\
\hline & Outros & 57 & $67,86 \%$ \\
\hline \multirow{2}{*}{ Local de Trabalho (Estado) } & São Paulo & 29 & $34,52 \%$ \\
\hline & Outros & 55 & $65,48 \%$ \\
\hline
\end{tabular}

Fonte: Autores.

De acordo com os dados presentes na Tabela 3, destacam-se alguns critérios:

- $\quad$ Mais da metade dos indivíduos $(60,71 \%)$ eram engenheiros.

- Quase um terço dos indivíduos $(32,14 \%)$ trabalhavam em empresas com ramo de atividade de energia. 
- Mais de um terço dos indivíduos (34,52\%) Trabalhavam em São Paulo.

A Tabela 4, cujos dados apresentam a análise puramente descritiva dos itens de cada constructo.

Tabela 4: Análise descritiva e comparação dos itens dos constructos.

\begin{tabular}{|c|c|c|c|c|c|}
\hline Constructo & Item & $\mathbf{N}$ & Média & D.P. & I.C. $95 \%$ \\
\hline \multirow{3}{*}{ Risco Político } & $\mathrm{RP} 2$ & 84 & 7,48 & 1,97 & {$[7,04 ; 7,89]$} \\
\hline & RP3 & 84 & 7,01 & 1,92 & {$[6,62 ; 7,41]$} \\
\hline & RP1 & 84 & 6,60 & 1,90 & {$[6,18 ; 6,98]$} \\
\hline \multirow{5}{*}{ Risco Econômico } & RE1 & 84 & 8,02 & 1,48 & {$[7,69 ; 8,35]$} \\
\hline & RE2 & 84 & 6,43 & 1,90 & {$[6,02 ; 6,83]$} \\
\hline & RE4 & 84 & 6,13 & 2,21 & {$[5,65 ; 6,6]$} \\
\hline & RE5 & 84 & 5,62 & 1,95 & {$[5,2 ; 6,01]$} \\
\hline & RE3 & 84 & 4,83 & 2,10 & {$[4,38 ; 5,27]$} \\
\hline \multirow{6}{*}{ Risco Social } & RS6 & 84 & 5,67 & 2,34 & {$[5,14 ; 6,18]$} \\
\hline & RS5 & 84 & 5,60 & 2,12 & {$[5,15 ; 6,02]$} \\
\hline & RS4 & 84 & 5,30 & 2,22 & {$[4,83 ; 5,74]$} \\
\hline & RS3 & 84 & 4,94 & 2,58 & {$[4,4 ; 5,54]$} \\
\hline & RS1 & 84 & 4,08 & 2,49 & {$[3,56 ; 4,63]$} \\
\hline & RS2 & 84 & 3,01 & 2,18 & {$[2,56 ; 3,48]$} \\
\hline \multirow{10}{*}{ Risco Tecnológico } & RT10 & 84 & 6,55 & 2,29 & {$[6,07 ; 7]$} \\
\hline & RT9 & 84 & 6,07 & 2,12 & {$[5,6 ; 6,54]$} \\
\hline & RT2 & 84 & 5,89 & 1,83 & {$[5,55 ; 6,32]$} \\
\hline & RT4 & 84 & 5,54 & 1,92 & {$[5,14 ; 5,93]$} \\
\hline & RT7 & 84 & 5,39 & 2,18 & {$[4,93 ; 5,87]$} \\
\hline & RT1 & 84 & 5,18 & 1,94 & {$[4,77 ; 5,6]$} \\
\hline & RT3 & 84 & 4,73 & 1,85 & {$[4,31 ; 5,08]$} \\
\hline & RT8 & 84 & 4,68 & 2,00 & {$[4,27 ; 5,13]$} \\
\hline & RT6 & 84 & 4,60 & 1,99 & {$[4,2 ; 5,04]$} \\
\hline & RT5 & 84 & 3,31 & 2,17 & {$[2,86 ; 3,77]$} \\
\hline \multirow{2}{*}{ Risco Legal } & RL1 & 84 & 5,40 & 2,26 & {$[4,94 ; 5,89]$} \\
\hline & RL2 & 84 & 5,21 & 2,45 & {$[4,69 ; 5,73]$} \\
\hline \multirow{8}{*}{ Risco Ambiental } & RA5 & 84 & 7,18 & 2,05 & {$[6,71 ; 7,61]$} \\
\hline & RA3 & 84 & 5,26 & 2,38 & {$[4,75 ; 5,77]$} \\
\hline & RA4 & 84 & 5,08 & 2,38 & {$[4,61 ; 5,55]$} \\
\hline & RA7 & 84 & 4,83 & 2,23 & {$[4,37 ; 5,29]$} \\
\hline & RA1 & 84 & 4,81 & 2,27 & {$[4,31 ; 5,32]$} \\
\hline & RA8 & 84 & 4,70 & 2,23 & {$[4,21 ; 5,18]$} \\
\hline & RA6 & 84 & 4,58 & 2,42 & {$[4,07 ; 5,06]$} \\
\hline & RA2 & 84 & 4,32 & 2,60 & {$[3,76 ; 4,87]$} \\
\hline
\end{tabular}

Fonte: Autores.

A Tabela 5 apresenta uma organização decrescente, com caráter comparativo entre os itens calculados e apresentados pela Tabela 4 . 
Tabela 5: Análise descritiva e comparação dos itens.

\begin{tabular}{|c|c|c|c|c|}
\hline Item & $\mathbf{N}$ & Média & D.P. & I.C. $95 \%$ \\
\hline RE1 & 84 & 8,02 & 1,48 & {$[7,69 ; 8,35]$} \\
\hline RP2 & 84 & 7,48 & 1,97 & {$[7,04 ; 7,89]$} \\
\hline RA5 & 84 & 7,18 & 2,05 & {$[6,71 ; 7,61]$} \\
\hline RP3 & 84 & 7,01 & 1,92 & {$[6,62 ; 7,41]$} \\
\hline RP1 & 84 & 6,60 & 1,90 & {$[6,18 ; 6,98]$} \\
\hline RT10 & 84 & 6,55 & 2,29 & {$[6,07 ; 7]$} \\
\hline RE2 & 84 & 6,43 & 1,90 & {$[6,02 ; 6,83]$} \\
\hline RE4 & 84 & 6,13 & 2,21 & {$[5,65 ; 6,6]$} \\
\hline RT9 & 84 & 6,07 & 2,12 & {$[5,6 ; 6,54]$} \\
\hline RT2 & 84 & 5,89 & 1,83 & {$[5,55 ; 6,32]$} \\
\hline RS6 & 84 & 5,67 & 2,34 & {$[5,14 ; 6,18]$} \\
\hline RE5 & 84 & 5,62 & 1,95 & {$[5,2 ; 6,01]$} \\
\hline RS5 & 84 & 5,60 & 2,12 & {$[5,15 ; 6,02]$} \\
\hline RT4 & 84 & 5,54 & 1,92 & {$[5,14 ; 5,93]$} \\
\hline RL1 & 84 & 5,40 & 2,26 & {$[4,94 ; 5,89]$} \\
\hline RT7 & 84 & 5,39 & 2,18 & {$[4,93 ; 5,87]$} \\
\hline RS4 & 84 & 5,30 & 2,22 & {$[4,83 ; 5,74]$} \\
\hline RA3 & 84 & 5,26 & 2,38 & {$[4,75 ; 5,77]$} \\
\hline RL2 & 84 & 5,21 & 2,45 & {$[4,69 ; 5,73]$} \\
\hline RT1 & 84 & 5,18 & 1,94 & {$[4,77 ; 5,6]$} \\
\hline RA4 & 84 & 5,08 & 2,38 & {$[4,61 ; 5,55]$} \\
\hline RS3 & 84 & 4,94 & 2,58 & {$[4,4 ; 5,54]$} \\
\hline RE3 & 84 & 4,83 & 2,10 & {$[4,38 ; 5,27]$} \\
\hline RA7 & 84 & 4,83 & 2,23 & {$[4,37 ; 5,29]$} \\
\hline RA1 & 84 & 4,81 & 2,27 & {$[4,31 ; 5,32]$} \\
\hline RT3 & 84 & 4,73 & 1,85 & {$[4,31 ; 5,08]$} \\
\hline RA8 & 84 & 4,70 & 2,23 & {$[4,21 ; 5,18]$} \\
\hline RT8 & 84 & 4,68 & 2,00 & {$[4,27 ; 5,13]$} \\
\hline RT6 & 84 & 4,60 & 1,99 & {$[4,2 ; 5,04]$} \\
\hline RA6 & 84 & 4,58 & 2,42 & {$[4,07 ; 5,06]$} \\
\hline RA2 & 84 & 4,32 & 2,60 & {$[3,76 ; 4,87]$} \\
\hline RS1 & 84 & 4,08 & 2,49 & {$[3,56 ; 4,63]$} \\
\hline RT5 & 84 & 3,31 & 2,17 & {$[2,86 ; 3,77]$} \\
\hline $\mathrm{RS} 2$ & 84 & 3,01 & 2,18 & {$[2,56 ; 3,48]$} \\
\hline
\end{tabular}

Fonte: Autores.

Vale ressaltar que a escala de percepção de ocorrência para cada risco foi fixada em uma escala com valores entre 0 e 10 e os itens de cada constructo estão organizados por valores que partem da maior média de frequência para a menor. Dessa forma, algumas considerações foram desenvolvidas, onde destacam-se:

i. No constructo Risco Político, o item que os indivíduos tendem achar que tem maior risco de ocorrer é o RP2 “Risco País (Instabilidade política, Eleições)” e o que tem menos riso de ocorrer é o item RP1 "Risco Regulatório (Mudanças nos esquemas de suporte a políticas, Responsabilidade perante terceiros)". Além disso, analisando os intervalos de confiança, observa-se que a média do item RP2 foi significativamente maior que a média do item RP1, pois os intervalos não se sobrepuseram.

ii. No constructo Risco Econômico, o item que os indivíduos tendem achar que tem maior risco de ocorrer é o RE1 "Burocracia (Processos de aprovação complexos, Atrasos de licenças)" e o que tem menos riso de ocorrer é o item RE3 "Danos à reputação". Além disso, analisando os intervalos de confiança, observa-se que a média do item RE1 foi significativamente maior que a média dos demais itens, a média do item RE2 foi significativamente maior que a média dos itens RE4, RE5 e RE3, e a média do item RE3 foi significativamente menor que a média dos itens RE1, RE2 e RE4, pois os 
intervalos não se sobrepuseram.

iii. No constructo Risco Social, o item que os indivíduos tendem achar que tem maior risco de ocorrer é o RS6 "Incremento dos conflitos com as comunidades tradicionais e indígenas" e o que tem menos riso de ocorrer é o item RS2 "Riscos para a saúde (Acidentes, Doenças agudas)". Além disso, analisando os intervalos de confiança, observa-se que a média do item RS1 foi significativamente menor que a média dos itens RS4, RS5 e RS6, e a média do item RS2 foi significativamente menor que a média dos demais itens, pois os intervalos não se sobrepuseram.

iv. No constructo Risco Tecnológico, o item que os indivíduos tendem achar que tem maior risco de ocorrer é o RT10 "Conexão da rede" e o que tem menos riso de ocorrer é o item RT5 "Sabotagem, terrorismo, roubo". Além disso, analisando os intervalos de confiança, observa-se que a média do item RT10 foi significativamente maior que a média dos itens RT4, RT7, RT1, RT3, RT8, RT6 e RT5, a média do item RT5 foi significativamente menor que a média dos demais itens, e a média dos itens RT3, RT8 e RT6 foram significativamente menores que as média dos itens RT10, RT9, RT2 e RT4, pois os intervalos não se sobrepuseram.

v. No constructo Risco Legal, o item que os indivíduos tendem achar que tem maior risco de ocorrer é o RL1 "Políticas energéticas e mudanças climáticas" e o que tem menos riso de ocorrer é o item RL2 "Ausência de legislação específica". Mas não houve diferença significativa entre eles, pois os intervalos se sobrepuseram.

vi. No constructo Risco Ambiental, o item que os indivíduos tendem achar que tem maior risco de ocorrer é o RA5 "Atrasos na emissão das licenças ambientais" e o que tem menos riso de ocorrer é o item RA2 "Pegada de carbono e avaliação do ciclo de vida". Além disso, analisando os intervalos de confiança, observa-se que a média do item RA5 foi significativamente maior que a média dos demais itens, pois os intervalos não se sobrepuseram.

\subsection{Análise estatística inferencial}

A fim de criar indicadores que representassem os constructos foi utilizada Análise Fatorial Exploratória (AFE), que teve como objetivo verificar a necessidade de exclusão de algum item que não estivesse contribuindo com a formação dos constructos, uma vez que de acordo com Hair et al (2009) itens com cargas fatoriais menores que 0,50 devem ser eliminados dos constructos, pois, ao não contribuir de forma relevante para formação da variável latente, prejudicam o alcance das suposições básicas para validade e qualidade dos indicadores criados para representar o conceito de interesse. A Tabela 6 apresenta a carga fatorial, a comunalidade e o peso de cada item.

Tabela 6: Análise Fatorial dos constructos.

\begin{tabular}{|c|c|c|c|c|}
\hline \multirow{2}{*}{ Constructo } & \multirow{2}{*}{ Item } & \multicolumn{3}{|c|}{ Modelo } \\
\hline & & Carga Fatorial & Comunalidade & Peso \\
\hline \multirow{3}{*}{ Risco Político } & RP1 & 0,75 & 0,56 & 0,46 \\
\hline & RP2 & 0,78 & 0,62 & 0,48 \\
\hline & RP3 & 0,68 & 0,47 & 0,41 \\
\hline \multirow{5}{*}{ Risco Econômico } & RE1 & 0,46 & 0,21 & 0,20 \\
\hline & RE2 & 0,67 & 0,45 & 0,28 \\
\hline & RE3 & 0,70 & 0,49 & 0,30 \\
\hline & RE4 & 0,79 & 0,62 & 0,33 \\
\hline & RE5 & 0,76 & 0,58 & 0,32 \\
\hline \multirow{6}{*}{ Risco Social } & RS1 & 0,62 & 0,39 & 0,19 \\
\hline & $\mathrm{RS} 2$ & 0,72 & 0,52 & 0,21 \\
\hline & RS3 & 0,79 & 0,62 & 0,23 \\
\hline & RS4 & 0,82 & 0,68 & 0,24 \\
\hline & RS5 & 0,74 & 0,55 & 0,22 \\
\hline & RS6 & 0,78 & 0,61 & 0,23 \\
\hline
\end{tabular}




\begin{tabular}{|c|c|c|c|c|}
\hline \multirow{10}{*}{ Risco Tecnológico } & RT1 & 0,69 & 0,47 & 0,15 \\
\hline & RT2 & 0,62 & 0,38 & 0,14 \\
\hline & RT3 & 0,69 & 0,47 & 0,15 \\
\hline & RT4 & 0,72 & 0,52 & 0,16 \\
\hline & RT5 & 0,54 & 0,29 & 0,12 \\
\hline & RT6 & 0,68 & 0,46 & 0,15 \\
\hline & RT7 & 0,76 & 0,58 & 0,17 \\
\hline & RT8 & 0,67 & 0,45 & 0,15 \\
\hline & RT9 & 0,75 & 0,57 & 0,17 \\
\hline & RT10 & 0,51 & 0,26 & 0,11 \\
\hline \multirow{2}{*}{ Risco Legal } & RL1 & 0,86 & 0,74 & 0,58 \\
\hline & RL2 & 0,86 & 0,74 & 0,58 \\
\hline \multirow{8}{*}{ Risco Ambiental } & RA1 & 0,74 & 0,54 & 0,19 \\
\hline & RA2 & 0,71 & 0,51 & 0,18 \\
\hline & RA3 & 0,74 & 0,55 & 0,19 \\
\hline & RA4 & 0,72 & 0,52 & 0,18 \\
\hline & RA5 & 0,59 & 0,35 & 0,15 \\
\hline & RA6 & 0,75 & 0,56 & 0,19 \\
\hline & RA7 & 0,72 & 0,52 & 0,18 \\
\hline & RA8 & 0,65 & 0,42 & 0,16 \\
\hline
\end{tabular}

Fonte: Autores.

Importante destacar que o item RE1 do constructo Risco Econômico, apesar de ter CF menor que 0,50 não interferiu para validação do modelo e, por esse motivo, não foi excluído. A Tabela 7 contempla a verificação das medidas de validade e qualidade dos constructos.

Tabela 7: Validação dos constructos.

\begin{tabular}{lcccccc}
\hline \multicolumn{1}{c}{ Constructo } & Itens & Variância Extraída & Alfa de Cronbach & Confiabilidade Composta & KMO & Dimensionalidade \\
\hline Risco Político & 3 & 0,55 & 0,59 & 0,70 & 0,62 & 1 \\
\hline Risco Econômico & 5 & 0,47 & 0,72 & 0,75 & 0,69 & 1 \\
\hline Risco Social & 6 & 0,56 & 0,84 & 0,83 & 0,83 & 1 \\
\hline Risco Tecnológico & 10 & 0,45 & 0,86 & 0,85 & 0,82 & 1 \\
\hline Risco Legal & 2 & 0,74 & 0,64 & 0,76 & 0,50 & 1 \\
\hline Risco Ambiental & 8 & 0,50 & 0,85 & 0,84 & 0,81 & 1 \\
\hline
\end{tabular}

Fonte: Autores.

Com base nos resultados na Tabela 7, pode-se verificar que:

i. Todos os constructos apresentaram validação convergente (AVE > 0,40);

ii. Todos os constructos apresentaram Alfa de Cronbach $(\alpha)$ e/ou Confiabilidade Composta (CC) acima de 0,60, ou seja, todos apresentaram os níveis exigidos de confiabilidade.

iii. Em todos os constructos, o ajuste da Análise Fatorial Exploratória foi adequado, uma vez que todos os KMO foram maiores ou iguais a 0,50 .

iv. Todos os constructos foram unidimensionais pelo critério das retas paralelas.

A Tabela 8 apresenta a análise descritiva dos indicadores criados, tendo a Figura 1 caracterizada pelo gráfico que ilustra com maiores detalhes a análise da Tabela 8 . 
Tabela 8: Análise descritiva dos Indicadores.

\begin{tabular}{lcccccccc}
\hline Constructo & $\mathbf{N}$ & Média & Desvio Padrão & Mínimo & $\mathbf{1}^{\mathbf{0}} \mathbf{Q}$ & $\mathbf{2}^{\mathbf{0}} \mathbf{Q}$ & $\mathbf{3}^{\circ} \mathbf{Q}$ & Máximo \\
\hline Risco Político & 84 & 7,04 & 1,43 & 1,71 & 6,03 & 7,32 & 8,05 & 9,65 \\
\hline Risco Econômico & 84 & 6,06 & 1,39 & 2,61 & 5,09 & 6,15 & 7,06 & 8,97 \\
\hline Risco Legal & 84 & 5,31 & 2,02 & 1,00 & 4,00 & 5,50 & 7,00 & 10,00 \\
\hline Risco Tecnológico & 84 & 5,21 & 1,36 & 1,21 & 4,41 & 5,23 & 6,15 & 7,83 \\
\hline Risco Ambiental & 84 & 5,05 & 1,65 & 1,25 & 3,74 & 5,17 & 6,34 & 7,85 \\
\hline Risco Social & 84 & 4,81 & 1,74 & 1,22 & 3,58 & 4,98 & 5,85 & 9,84 \\
\hline
\end{tabular}

Fonte: Autores.

Figura 3: Gráfico analítico do radar dos indicadores.

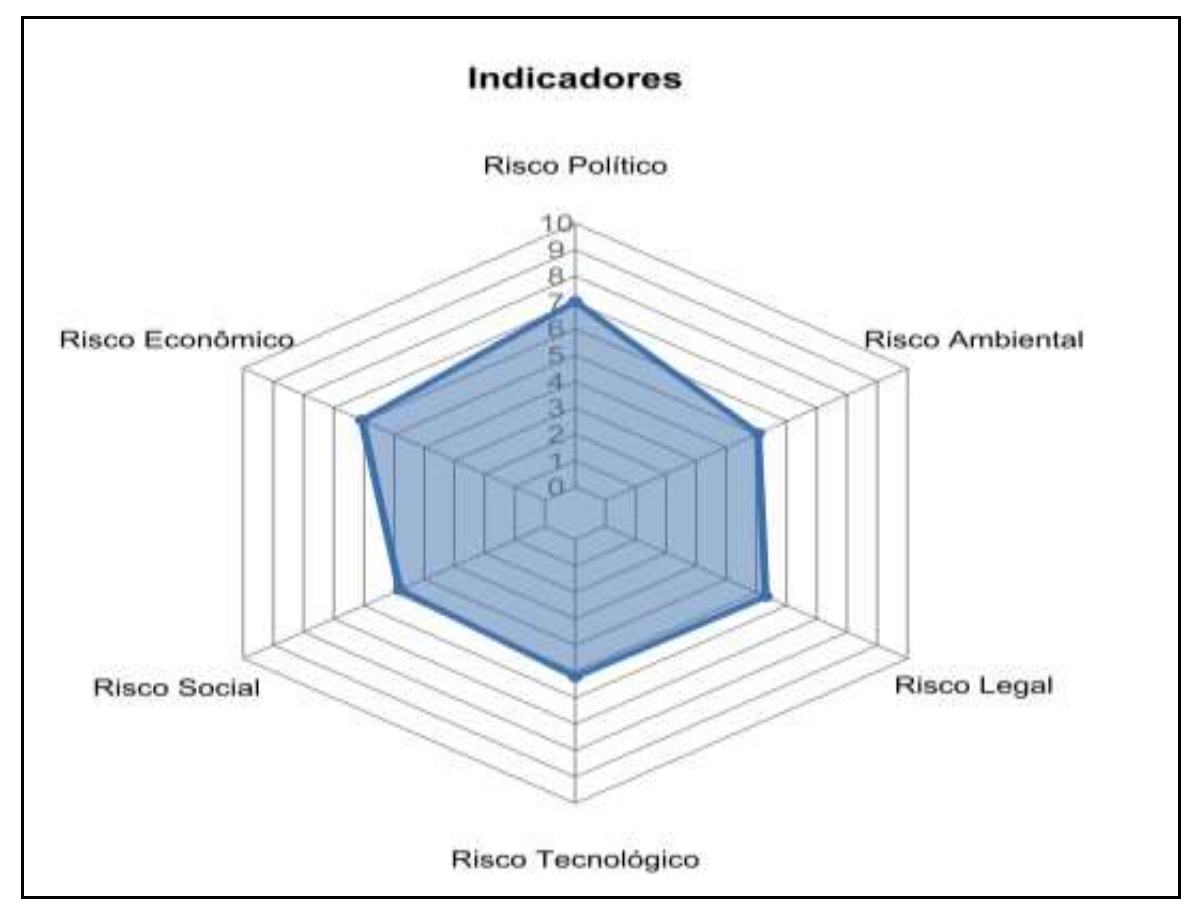

Fonte: Autores.

Com base nos dados apresentados na Tabela 8, análise descritiva dos indicadores criados, e representados pela Figura 3, gráfico analítico do radar dos indicadores, verificou-se alguns aspectos relevantes:

i. A média do indicador Risco Político foi de 7,04, com desvio padrão de 1,43 . Já o $1^{\text {a }}$ e $3^{\circ}$ quartis foram de 6,03 e 8,05 , respectivamente, ou seja, $25 \%$ dos indivíduos achavam que o risco de ocorrer era igual ou menor que 6,03 e $75 \%$ achavam que era igual ou menor que 8,05, com valores entre 1,71 e 9,65;

ii. A média do indicador Risco Econômico foi de 6,06, com desvio padrão de 1,39. Já o $1^{\text {a }}$ e $3^{\circ}$ quartis foram de 5,09 e 7,06, respectivamente, ou seja, 25\% dos indivíduos achavam que o risco de ocorrer era igual ou menor que 5,09 e $75 \%$ achavam que era igual ou menor que 7,06, com valores entre 2,61 e 8,97;

iii. A média do indicador Risco Legal foi de 5,31, com desvio padrão de 2,02. Já o $1^{\text {a }}$ e $3^{\circ}$ quartis foram de 4 e 7 , respectivamente, ou seja, $25 \%$ dos indivíduos achavam que o risco de ocorrer era igual ou menor que 4 e $75 \%$ achavam que era igual ou menor que 7 , com valores entre 1 e 10 ;

iv. A média do indicador Risco Tecnológico foi de 5,21, com desvio padrão de 1,36 . Já o $1^{\text {a }}$ e $3^{\circ}$ quartis foram de 4,41 e 6,15 , respectivamente, ou seja, $25 \%$ dos indivíduos achavam que o risco de ocorrer era igual ou menor que 4,41 e $75 \%$ achavam que era igual ou menor que 6,15 , com valores entre 1,21 e 7,83 ; 
v. A média do indicador Risco Ambiental foi de 5,05, com desvio padrão de 1,65. Já o $1^{\text {a }}$ e $3^{\circ}$ quartis foram de 3,74 e 6,34, respectivamente, ou seja, $25 \%$ dos indivíduos achavam que o risco de ocorrer era igual ou menor que 3,74 e $75 \%$ achavam que era igual ou menor que 6,34, com valores entre 1,25 e 7,85;

vi. A média do indicador Risco Social foi de 4,81, com desvio padrão de 1,74. Já o $1^{\text {a }}$ e $3^{\text {o }}$ quartis foram de 3,58 e 5,85, respectivamente, ou seja, $25 \%$ dos indivíduos achavam que o risco de ocorrer era igual ou menor que 3,58 e $75 \%$ achavam que era igual ou menor que 5,85, com valores entre 1,22 e 9,84;

O indicador que apresenta maior frequência é o Risco Político, seguido pelo indicador Risco Econômico, depois temse Risco Legal e Risco Tecnológico e com menores frequência tem-se os indicadores Risco Ambiental e Risco Social.

\section{Considerações Finais}

Com base nos dados presentes na literatura acadêmica, foram identificadas seis categorias de riscos (Políticos; Econômicos; Legais; Tecnológicos; Ambientais; e sociais), onde foi possível especificar e analisar 34 diferentes fatores de risco associados diretamente a projetos de energia eólica.

A partir da definição de uma lista completa e especificada para cada um desses 34 fatores de risco, foi elaborado um instrumento de pesquisa, de natureza quantitativa, que foi respondido por 84 profissionais com experiência direta ou indireta no setor de energia eólica. As análises tornaram possível classificar os fatores de risco identificados previamente na pesquisa bibliografia consultada, conseguindo a partir disto, hierarquizar os riscos identificados e classificados, segundo a média do grau de impacto de cada risco.

Os resultados contemplados pelas análises quantificativas fundamentam satisfatoriamente o propósito da pesquisa, que consiste na identificação, classificação e hierarquização dos fatores de risco associado a projetos e à gestão de geração de energia eólica.

Com base no Quadro 4, foi possível detectar que a categoria de risco com maior potencial de ocorrência e impacto é relacionada a riscos políticos, seguida por riscos econômicos. Depois, em nível de menor relevância, tem-se os riscos legais, tecnológicos, ambientais e sociais, respectivamente. Dentro dessas categorias de risco, verificou-se que o fator de risco com maior potencial de ocorrência e impacto está associado à burocracia, cujo escopo corresponde aos riscos relativos aos processos de aprovação para situações complexas e atrasos nos prazos para as obtenções de licenças.

Em suma, a síntese de toda pesquisa desenvolvida, tal como descrita acima, tanto no que diz respeito à consulta bibliográfica, como à consulta a profissionais especialistas, por meio de questionário, segue fundamentada pelos Quadros 4 e 5 .

Quadro 4: Classificação por média de grau de impacto dos fatores riscos de gestão de projeto de geração de energia eólica.

\begin{tabular}{|c|c|c|c|}
\hline Categoria & Grau & Fatores de Risco & Referências \\
\hline \multirow{3}{*}{ Político } & 7,48 & Risco País (Instabilidade política, Eleições) & $\begin{array}{l}\text { (Ioannou, Angusb \& Brennana, } \\
\text { 2017) }\end{array}$ \\
\hline & 7,01 & $\begin{array}{l}\text { Risco contratual (Previsão de penalidades por atraso e custos com } \\
\text { licenças ambientais) }\end{array}$ & $\begin{array}{l}\text { (Ioannou, Angusb \& Brennana, } \\
\text { 2017) }\end{array}$ \\
\hline & 6,60 & $\begin{array}{l}\text { Risco Regulatório (Mudanças nos esquemas de suporte a políticas, } \\
\text { responsabilidade perante terceiros) }\end{array}$ & $\begin{array}{l}\text { (Ioannou, Angusb \& Brennana, } \\
\text { 2017) }\end{array}$ \\
\hline \multirow{2}{*}{ Econômico } & 8,02 & Burocracia (Processos de aprovação complexos, Atrasos de licenças) & $\begin{array}{c}\text { (Ioannou, Angusb \& Brennana, } \\
\text { 2017) }\end{array}$ \\
\hline & 6,43 & $\begin{array}{l}\text { Mercado (Variabilidade de receita devido ao preço da eletricidade, } \\
\text { flutuação de demanda) }\end{array}$ & $\begin{array}{l}\text { (Ioannou, Angusb \& Brennana, } \\
\text { 2017) }\end{array}$ \\
\hline
\end{tabular}




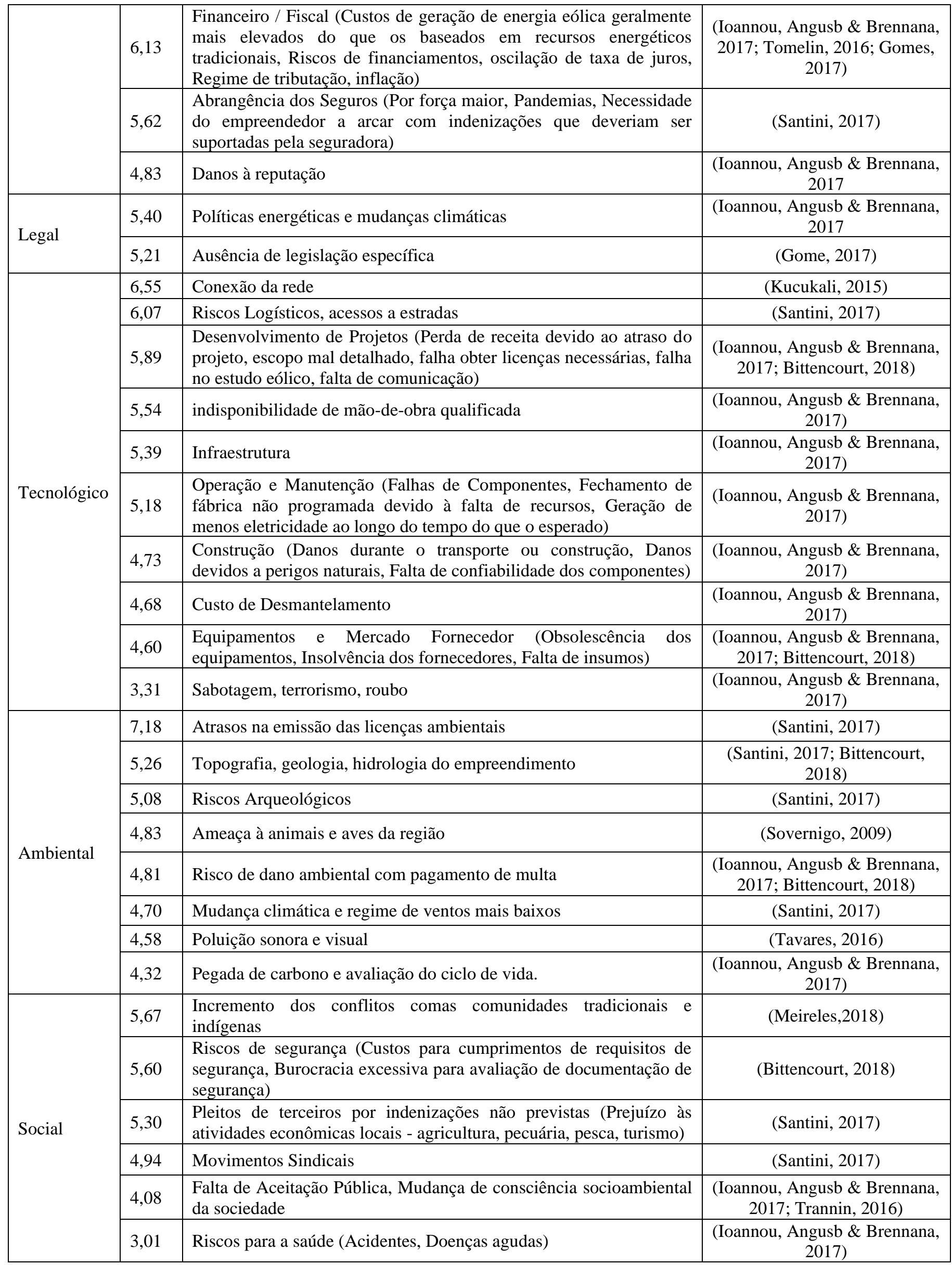


Fonte: Autores.

O Quadro 4 aborda a classificação, por média de grau de impacto dos riscos de gestão de projeto de geração de energia eólica, identificando cada fator de risco e fazendo os respectivos agrupamentos, conforme cada categoria de risco, seguido da média do grau de impacto. Além disso, o quadro indica as principais referências consultadas para a identificação e definição de cada fator de risco.

Quadro 5: Hierarquização dos fatores de risco em projetos de energia eólica, segundo as médias de graus de impacto.

\begin{tabular}{|c|c|}
\hline Posição & Categoria do Risco \\
\hline 1 & Burocracia (Processos de aprovação complexos, Atrasos de licenças) \\
\hline 2 & Risco País (Instabilidade política, Eleições) \\
\hline 3 & Atrasos na emissão das licenças ambientais \\
\hline 4 & Risco contratual (Previsão de penalidades por atraso e custos com licenças ambientais) \\
\hline 5 & Risco Regulatório (Mudanças nos esquemas de suporte a políticas, Responsabilidade perante terceiros) \\
\hline 6 & Conexão da rede \\
\hline 7 & Mercado (Variabilidade de receita devido ao preço da eletricidade, Flutuação de demanda) \\
\hline 8 & $\begin{array}{l}\text { Financeiro/ Fiscal (Custos de geração de energia eólica geralmente mais elevados do que os baseados } \\
\text { em recursos energéticos tradicionais, Riscos de financiamentos, Oscilação de taxa de juros, Regime de tributação, } \\
\text { Inflação) }\end{array}$ \\
\hline 9 & Riscos Logísticos, acessos a estradas \\
\hline 10 & $\begin{array}{l}\text { Desenvolvimento de Projetos (Perda de receita devido ao atraso do projeto, Escopo mal detalhado, Falha para obter } \\
\text { licenças necessárias, Falha no estudo eólico, Falta de comunicação) }\end{array}$ \\
\hline 11 & Incremento dos conflitos com as comunidades tradicionais e indígenas \\
\hline 12 & $\begin{array}{l}\text { Abrangência dos Seguros (Por força maior, Pandemias, Necessidade do empreendedor a arcar com indenizações que } \\
\text { deveriam ser suportadas pela seguradora) }\end{array}$ \\
\hline 13 & $\begin{array}{l}\text { Riscos de Segurança (Custos para cumprimentos de requisitos de segurança, Burocracia excessiva para avaliação de } \\
\text { documentação de segurança) }\end{array}$ \\
\hline 14 & Indisponibilidade de mão-de-obra qualificada \\
\hline 15 & Políticas energéticas e mudanças climáticas \\
\hline 16 & Infraestrutura \\
\hline 17 & $\begin{array}{l}\text { Pleitos de terceiros por indenizações não previstas (Prejuízo às atividades econômicas locais - agricultura, pecuária, } \\
\text { pesca, turismo) }\end{array}$ \\
\hline 18 & Topografia, geologia, hidrologia do empreendimento \\
\hline 19 & Ausência de legislação específica \\
\hline 20 & $\begin{array}{l}\text { Operação e Manutenção (Falhas de Componentes, Fechamento de fábrica não programada devido à falta de } \\
\text { recursos, Geração de menos eletricidade ao longo do tempo do que o esperado) }\end{array}$ \\
\hline 21 & Riscos Arqueológicos \\
\hline 22 & Movimentos Sindicais \\
\hline 23 & Danos à rep ut ação \\
\hline 24 & Ameaça à animais e aves da região \\
\hline 25 & Risco de dano ambiental com pagamento de multa \\
\hline 26 & $\begin{array}{l}\text { Construção (Danos durante o transporte ou construção, Danos devidos a perigos naturais, Falta de confiabilidade } \\
\text { dos componentes) }\end{array}$ \\
\hline 27 & Mudança climática $e$ regime de ventos mais baixos \\
\hline
\end{tabular}


Research, Society and Development, v. 10, n. 14, e490101422011, 2021

(CC BY 4.0) | ISSN 2525-3409 | DOI: http://dx.doi.org/10.33448/rsd-v10i14.22011

\begin{tabular}{|c|l|}
\hline 28 & Custo de Desmantelamento \\
\hline 29 & $\begin{array}{l}\text { Equipamentos e Mercado Fornecedor (Obsolescência dos equipamentos, Insolvência dos fornecedores, Falta de } \\
\text { insumos) }\end{array}$ \\
\hline 30 & Poluição sonora e visual \\
\hline 31 & Pegada de carbono e avaliação do ciclo de vida. \\
\hline 32 & Falta de Aceitação Pública, Mudança de consciência socioambiental da sociedade \\
\hline 33 & Sabotagem, terrorismo, roubo \\
\hline 34 & Riscos para a saúde (Acidentes, Doenças agudas) \\
\hline
\end{tabular}

Fonte: Autores.

O Quadro 5 trata da hierarquização dos fatores de risco em projetos de energia eólica, segundo as médias de graus de impacto, listando os 34 fatores de risco listados, segundo as médias de grau de impacto, para facilitar a visualização hierárquica de cada risco.

Com base no propósito da pesquisa, torna-se possível inferir que os Quadros 4 e 5 identificam e hierarquizam as categorias e os fatores de risco, de modo a auxiliar na previsão de criticidade presente na elaboração, implementação e gestão de projetos de investimentos de geração de energia eólica. Logo, este estudo, pode auxiliar no processo de decisão para investimentos associados às boas práticas de mercado, no que diz respeito a projetos de geração de energia eólica, ou de outras energias renováveis, uma vez que seu conteúdo pode servir como elemento comparativo para a análise de viabilidade para a implementação de projetos de geração de outras fontes de energias renováveis que tenham aspectos semelhantes à energia eólica.

Desta forma, a demanda energética tende a crescer com o desenvolvimento tecnológico que estamos passando, e a geração de energia eólica possui uma grande importância nos dias de hoje, construindo para um ambiente mais sustentável, que leve em consideração as gerações futuras.

Não obstante, é necessário levar em consideração que os fatores de risco levantados têm sua importância relativa, pois variam conforme o contexto pesquisado, alterando-se a medida de novos acontecimentos, como mudanças na economia, na política, na localização das empresas, entre outros. Portanto, os impactos dos fatores de risco devem ser revisados constantemente, uma que a presente pesquisa traz apenas uma fotografia do momento atual, isto é, os dados coletados são atinentes às especialidades da realidade da economia, política, legislação, tecnologia, meio ambiente e sociedade do país em 2020.

Sendo assim, mesmo que o estudo traga um mapa detalhado dos fatores de risco para projetos de gestão de geração de energia eólica no Brasil, vale ressaltar que é sempre importante analisar esses dados com a ressalta de que mudanças significativas do ambiente político, econômico, ou da oferta de tecnologia, ou mudança de legislação, requererá uma reavaliação da classificação e hierarquia desses riscos.

Como recomendação de futuras pesquisas, seria indicado tratar a respeito dos fatores de riscos em energia eólica contemplando outros países a fim de se comparar com o Brasil e realizar comparações com outras fontes de energias renováveis, tais como solar, biomassa, ondas e marés e geotérmica.

\section{Referências}

ABEEOLICA. Associação Brasileira de Energia Eólica (2020). http://abeeolica.org.br/energia-eolica-o-setor. Brasília: ABEEOLICA.

ABNT - Associação Brasileira de Normas Técnicas (2018). NBR ISO 31000:2018. Guia Para a Gestão de Riscos. Brasilia, 2018.

ANAEEL - Agência Nacional de Energia Elétrica (Brasil). Retrospectiva 2020 / Agência Nacional de Energia Elétrica. - Brasília: ANEEL, 2021. 
APM - Association for Project Management (1997) http://www.apm.org.uk.

Bhattacharya, A.; Kojima, S. (2012). Power sector investment risk and renewable energy: a Japanese case study using portfolio risk optimization method. Energy Policy, 69-80.

Bittencourt, E. G. (2018). Avaliação dos riscos em um contrato de preço global para implantação de um complexo eólico. Universidade Federal de Santa Catarina, Florianópolis.

Chin, W. W. (1998). The partial least squares approach to structural equation modeling. In: Methodology for business and management. Modern methods for business research. 1st. ed. Mahwah, NJ, US: Lawrence Erlbaum Associates Publishers.

Cicco, F.; Fantazzini, M. L. (2003). Tecnologias consagradas de gestão de riscos: riscos e probabilidades. São Paulo: Séries Risk Management, Risk Tecnologia Editora Ltda.

Efron, B.; TibshiranI, R.J. (1998). An Introduction to the Bootstrap. Champman \& Hall: Bookkman..

Fornell, C.; Larcker, D.F. Evaluating Structural Equation Models with Unobservable Variables and Measurement Error (1981). In: Journal of Marketing Research, v.18, n.1, 1-12.

Frankfurt School-UNEP CENTRE/BNEF (2020). Global trends in renewable energy investment https://www.fs-unep-centre.org/global-trends-in-renewableenergy-investment-2020/

Freitas, A. P. A., Santos, J. A. N. dos, Oliveira, E. P. de, Fernandes, D. R., \& Oliveira, N. L. F. de. (2021). Exploratory study of the dimensions of risks in civil construction projects. Research, Society and Development, 10(7), e14410716452. https://doi.org/10.33448/rsd-v10i7.16452.

Gomes, L. F. B. (2017). Análise de cenários de risco no controle de custos em projetos de usinas de energia renovável. Universidade Federal Fluminense, Niterói.

Hair, J. F. et al. (2009). Análise Multivariada de Dados. Porto Alegre: Editora Bookman.

Henseler, J. Ringle, C.M.; Sinkovics, R. R. (2009). The use of partial least squares path modeling in international marketing. Advances in International Marketing, v.20.

Hoyle, R. H.; Duvall,J.L.(2004). Determining the number of factors in exploratory and confirmatory analysis. In: D.Kaplan (Ed.): The Sage handbook of quantitative methodology for the social sciences. [S.1] Thousand Oaks, CA: Sage.

Ioannou,A., Angusb,A., Brennana,F.(2017). Risk-based methods for sustainable energy system planning: A review. Renewable and Sustainable Energy Reviews. 74, 602-615.

Keelling, R. (2006). Gestão de projetos: uma abordagem global. São Paulo: Editora: Saraiva.

Kucukali, S. (2015). Risk scorecard concept in wind energy projects: an integrated approach. Turquia.

MCTIC - Ministério da Ciência, Tecnologia e Inovação (2020) https://www.gov.br/mcti/pt-br.

Meireles, A. J. D. A. (2008) Danos socioambientais originados pelas usinas eólicas nos campos de dunas do nordeste brasileiro e critérios para definição de alternativas locacionais. Confins.

Mingoti, S. A. (2005). Análise de dados através de métodos de estatística multivariada: uma abordagem aplicada. Belo Horizonte: Editora UFMG, 2005.

Modarres, M. (2006). Risk analysis in engineering: techniques, tools, and trends. Boca Raton: Taylor \& Francis Group.

Nunnally, J. C.; Bernstein, I.H. (1994). Psychometric Theory. 3rd.ed. New York, N.Y.: Mc-Graw-Hill.

Perea,M. M. A, Hernandez,E.Q, (2018). Renewable Energy in Urban Areas: Worldwide Research Trends. Energies, $11(3), 577$.

Pereira Neto, A. (2014). A energia eólica no direito ambiental brasileiro. Rio de Janeiro: Editora Synergia.

PROJECT MANAGEMENT INSTITUTE (2017). Um guia do conjunto de conhecimentos do gerenciamento de projetos: PMBOK® Guide 6.ed. Newton Square: 14 Campus Boulevard.

Reis,P. (2009). Teoria e funcionamento da energia eólica https://www.portal-energia.com/teoria-energia-eolica/.

Santini, J. C. C. (2017). Gestão de riscos na implantação de projetos eólicos proposição de um modelo de análise de riscos. Universidade do Sul, Florianópolis

Simas, M.; Pacca, S. (2013) Energia eólica, geração de empregos e desenvolvimento sustentável. Revista Estudos Avançados, 99-15.

Sovernigo, M. H. (2009). Impacto dos aerogeradores sobre a avifauna e quiropterofauna no Brasil. Universidade Federal de Santa Catarina, Florianópolis.

Tavares, E. (2016). Energia eólica: viabilidade técnica e econômico-financeira. Universidade Federal de Ouro Preto, Ouro Preto.

Tenenhaus, M. et al. (2005). PLS path modeling. Computational Statistics and Data Analysis, 48(1), 159-205, Paris.

Trannin, M. (2016) Desafios e oportunidades para a geração de energia elétrica por fontes renováveis no brasil. Editora FGV Energia. 
Research, Society and Development, v. 10, n. 14, e490101422011, 2021

(CC BY 4.0) | ISSN 2525-3409 | DOI: http://dx.doi.org/10.33448/rsd-v10i14.22011

Valeriano, D. L. (1998) Gerencia em Projetos: Pesquisa, Desenvolvimento e Engenharia. Editora Makron Books.

Venchiarutti,M. M. (2102) Estudo sobre a viabilidade de Implementação de um aerogerador em uma cervejaria. Lorena. 